\title{
Improved Reaching Law Sliding Mode Control Algorithm Design For DC Motor Based on Kalman Filter
}

\author{
Min $\mathrm{Ma}^{1}$, Jueping $\mathrm{Bu}^{2, *}$ and Miaochao Chen ${ }^{3}$ \\ ${ }^{1}$ Basic Education Department of Jiangsu Food \& Pharmaceutical Science \\ College, Huaian, 223000, P. R. China \\ ${ }^{2,3}$ Department of Mathematics, Chaohu University, Hefei 238000. P. R. China \\ Imaminei@126.com, 2,"*bujueping@163.com \\ 3chenmiaochao@chu.edu.cn
}

\begin{abstract}
Aiming at the inaccurately modeling and some uncertain existing in servo system seriously affected the control quality and the instability problem, sliding mode control algorithm with improved reaching law is proposed in this paper. The improved reaching law is used to weaken the chattering problem existing in the sliding mode control. Also the kalman filter is used to inhibit the interference, which makes the servo system have strong anti-interference ability and the ability of weakening the chattering problem existing in the sliding mode control. The method of sliding mode control is the basis of a number of patents and patents pending. The simulation results show that the algorithm can effectively inhibit the external disturbance and noise existing in the system, and make the system have strong anti-interference ability. At the same time, the chattering also is obviously inhibited, and the method makes the system stability and control quality been further improved.
\end{abstract}

Keywords: DC Motor, SMC, Kalman Filter, Improved Reaching Law, Chattering, Simulation

\section{Introduction}

Sliding mode variable structure control is a special nonlinear control method, which is actually the discontinuity of control. The control strategy is different from other control method, because the structure of system is mainly unfixed, but the system can be changed in the dynamic process according to the current state of the system which is changed by some destination. And the method makes system move according to the state trajectory of sliding mode. Because the sliding mode can be designed and has nothing to do with the object parameter and disturbance, which makes the variable structure control have quick response, and be not sensitive to the disturbance and parameter change [1]. In the patent [2], a sliding mode control method was proposed. But due to the influence of factors such as time delay switch, spatial lag switch and the system inertia [3], it is difficult for the system to strictly sliding along the sliding mode for the balance, but crossing back and forth on both sides of the sliding mode surface to produce chattering. Due to vibration, it is easy to motivate the high frequency modeling dynamic in the system, and damage the system performance. In the later patents $[4,5]$, a sliding mode control apparatus and adjusting method and a mass flow controller employing sliding mode control were presented.

In practical engineering applications it also is involved in many fields, such as motor and power system control, robot control, flight control, satellite attitude control, etc. Researching on discrete time variable structure control system started in the $1980 \mathrm{~s}$. In 1980, Y. Dote puts forward the concept of "quasi sliding mode" [6], they extended the reaching condition of continuous system to the discrete system. In 1987 S. Z. Sarpturk 
etc., had proposed a new sliding mode reaching condition and proposed $\mathrm{r}$ theory that the discrete control signal must be bounded [7]. In 1990, K. Furuta proposed discrete sliding mode variable structure control and continuous control systems based on equivalent [8], and extended the reaching condition of continuous system to the discrete system and got new reaching condition that ensures the stability of the global sliding surface, the disadvantage is not suitable for multi-input systems. Chinese scholar Gao weibing had done a systematically study on the linear discrete variable structure control systems for the first time in 1995 [3], gave a definition and mathematical representation of quasisliding mode, rigorously proved the stability of quasi-sliding mode, discussed some basic properties of variable structural control, such as invariance and robustness, and gave the discrete sliding mode variable structure control index reaching law forms, the a discrete index reaching law is the most widely used design methods. However, due to defects existed in the index reaching law itself, the steady-state performance of the system is not ideal. Yao Qionghui pointed out that the use of the Gao approach to design control system can only be stable in the chattering zone near the origin in movement of the switching system and proposed a proportion - constant - shifting trends recent law that PCV control strategy in 2000 [9]. Zhai changlian and Wu Zhiming proposed an improved discrete index reaching law in 2000 [10], the proposed improved discrete index reaching law ensured the system to be stable at the origin of the movement, and has a good dynamic characteristic. Zhou Jinglin noted the above conditions are not satisfied reaching condition of discrete variable structure, and propose a shift attenuation reaching law [11]. Papers [12-14] gave the form of discrete reaching law. Smoothing the control signal is an effective way to eliminate chattering by using filters.

In order to eliminate the chattering of discrete sliding mode control, paper [15] designed two filters: the pre-filter and post-filter, where the pre-filter is designed for smoothing the control signal and narrowing boundary layer thickness of the saturation function, the post-filter is used to eliminate noise in the output. Paper [16] used a lowpass filter in the boundary layer of the switching function to obtain a smooth signal, and used the internal model principle to design a novel saturation function with integral and variable boundary layer thickness, it effectively reduced the chattering. In paper [17] using the physical characteristics of the robot a virtual sliding mode controller is designed to achieve a full robust variable structure control of the robot, and to ensure the stability of the system by adding low-pass filter at the controller output. This effectively eliminated chattering. In [18] designed variable structure controller with filter effectively eliminates chattering control signal obtained nonlinear controller to suppress high frequency noise, realized the existence of non-modeled dynamics of electro-hydraulic servo motor positioning control.

In order to overcome the sliding mode chattering problem, caused by dynamic unmodeled characteristics, paper [19] designed a new type of sliding mode controller, the controller output smooth controller output signal through a second-order filter, the auxiliary sliding surface coefficients were obtained by the sliding mode observe. Paper [20] proposed a new control law, the control law consists of three parts, the equivalent control, switching control and continuous control, in the control law used two low-pass filter, the gain of switching item was gotten through one low pass filter, and the get the equivalent controls law also was gotten through the other low pass filter, and the convergence and stability analysis were made, the proposed control algorithm effectively reduced chattering and achieved a high-performance control of multi-joint robot. 


\section{System Description}

\subsection{Working Principle of DC Motor}

With the development of the modern industry, DC motor is used as the Executive Termination for the servo system widely. The mathematical model of the magnetic brushless DC motor is established based on the working principle of magnetic brushless DC motor [21]. The working principle and the equivalent circuit diagram of DC motor was depicted in the following Figure (entitled Figure 1).
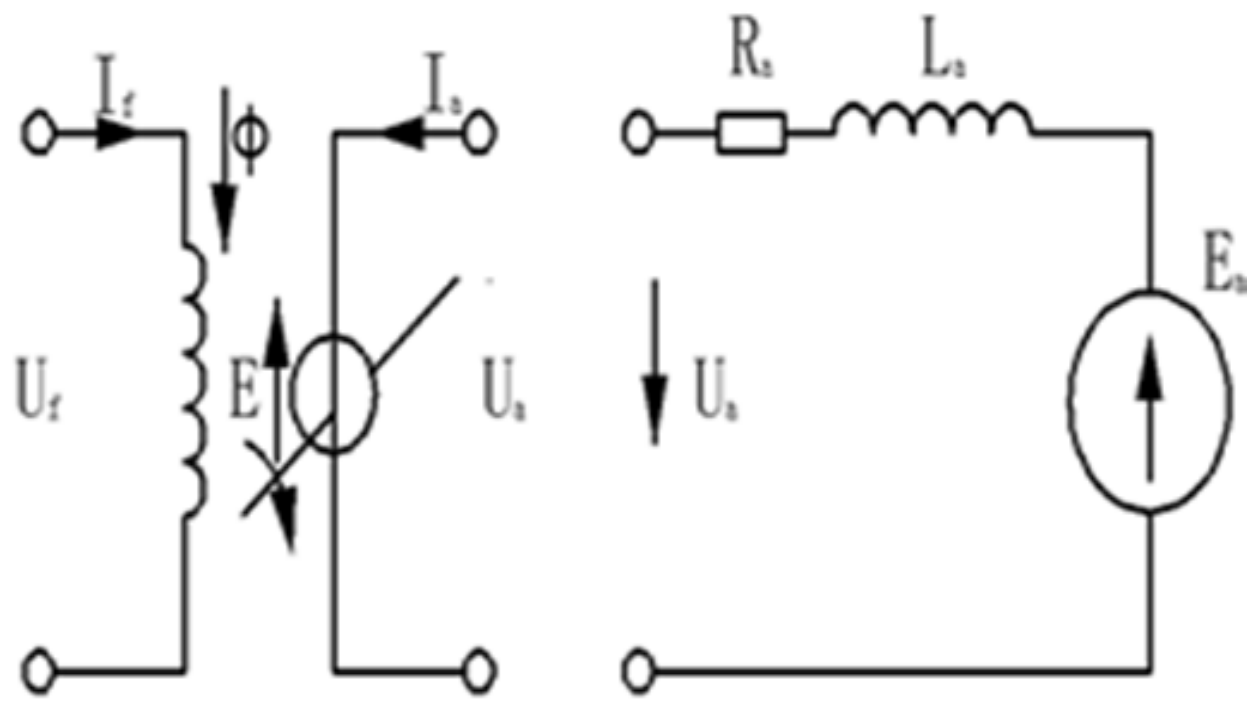

Figure 1. Working Principle and the Equivalent Circuit Diagram of DC Motor

\subsection{Mathematic Model}

From the working principle of magnetic brushless DC motor, we can obtain the voltage balance equation of DC motor armature circuit:

$U_{a}=E_{a}+R_{a} I_{a}=C_{E} \Phi_{n}+I_{a} R_{a}=K_{E} n+R_{a} I_{a}$

The DC motor's dynamic equation of is given as follows:

$$
u_{a}=K_{E} n+R_{a} i_{a}+L_{a} \frac{d i_{a}}{d t}
$$

In the equation (2), the parameter $R_{a}$ is the loop resistance, $I_{a}$ is the loop current, $E_{a}$ is the induction electromotive force, $U_{a}$ is the voltage of the circuit, $C_{a}$ is the electromotive force constant, $n$ is the motor's speed, $K_{E}$ is the electromotive force which is produced by unit speed.

Balanced equation of electrodynamics is as follows:

$T_{e}=B n+T_{L}+J \frac{d n}{d t}=C_{E} \Phi i_{a}=K_{T} i_{a}$

where $T_{e}$ is the instantaneous electromagnetic torque, $T_{L}$ is the load torque, $B$ is damping coefficient, $J$ is the moment of inertia, $K_{T}$ is torque constant. 
Assuming the initial conditions is zero, the motor load is constant, the equations are transformed by the Laplace. The transfer function of DC motor can be obtained as follows: $G(s)=\frac{n(s)}{U(s)}=\frac{K_{T}}{L_{a} J s^{2}+\left(R_{a} J+L_{a} B\right) s+R_{a} B+K_{T} K_{I}}$

\section{Design for Discrete Sliding Mode Controller}

\subsection{Reaching Law}

Domestic experts proposed the reaching law approach to reduce or inhibit the chattering of SMC in the premise of ensuring the condition of sliding existence $S S<0$ has been meet. And given four different methods of reaching law, such as constant reaching law, exponential approach law, power reaching law and general reaching law, where the exponential approach is applied widely [3], but the discrete form of exponential reaching law's switching zone is zonal. So this cannot be close to the origin ultimately but a chattering near the origin during the process moving [3]. In order to solve the chattering phenomenon of exponential reaching law near the origin $[22,23]$ proposed a variable rate reaching law for continuous system, it's discrete form as follows:

$$
S(k+1)-S(k)=-\varepsilon T\|X\|_{1} \operatorname{sgn}(S(k))
$$

where: $\|X\|_{1}--1$ norm of $\mathrm{x}$

Reaching speeds of variable rate reaching law is $\varepsilon\|X\|_{1}$, and is proportional to $\|X\|_{1}$. The switching zone pass through the origin with two rays, which can make $S=0$ in the middle of the two rays, can be stabilized at the origin, However, when the system just entered to switching zone $\|X\|_{1}$ will get a large value, and have a big chattering in SMC. In order overcome the problem of the variable rate reaching law and exponential approach law, [24] has proposed a new reaching law as follows:

$$
S(k+1)=(1-T q) S(k)-\varepsilon T \tan \operatorname{sig}\left(\|X\|_{1}\right) \operatorname{sgn}(S(k))
$$

where: $\tan \operatorname{sig}\left(\|X\|_{1}\right)=2 \operatorname{sig}\left(\|X\|_{1}\right)-1=\frac{1-e^{-\|x\|_{1}}}{1+e^{-\|X\|_{1}}}$.

\subsection{Design of Sliding Model Controller}

In this paper, in order to enhance the ability of anti-interference, and reduce the chattering of VSC, we made use improved reaching law and kalman filter to design the controller, the structure of the controller was shown in Figure 2 [25]. 


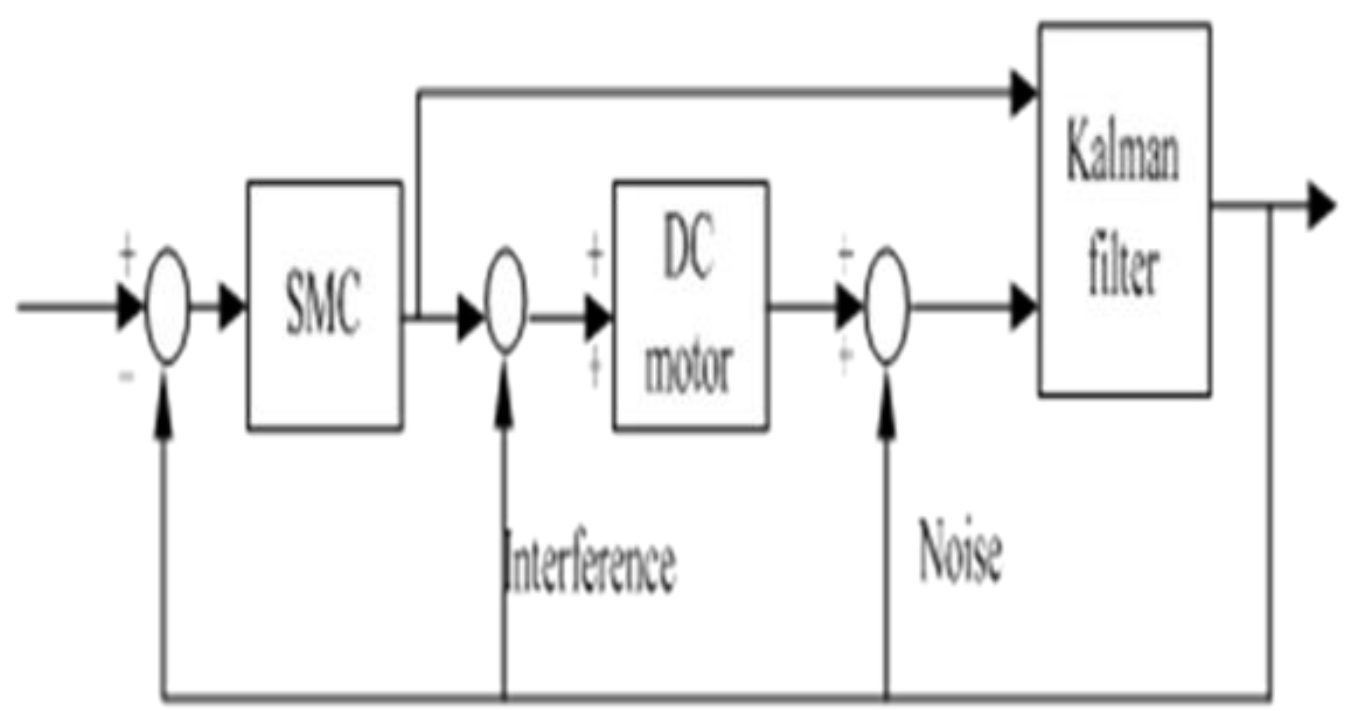

Figure 2. The Diagram of Controller

Assuming $\mathrm{G}(\mathrm{s})$ is the transfer function of servo system, and its state space equation as follow:

$$
x(k+1)=A x(k)+B u(k)
$$

where: $x(k)=\left[\begin{array}{ll}x_{1}(k) & x_{2}(k)\end{array}\right]^{T}$.

$x_{1}(k)$-- The actual velocity.

$x_{2}(k)$-- The actual velocity.

Supposed $r(k), d r(k)$ as the velocity order and it's change rate. $R_{k}=[r(k), d r(k)]$, predicted by linear extrapolation $R_{k+1}$ is:

$$
\begin{aligned}
r(k+1) & =2 r(k)-r(k-1) \\
d r(k+1) & =2 d r(k)-d r(k-1)
\end{aligned}
$$

Define switching function is:

$$
\begin{gathered}
S(k)=C_{e} E=C_{e}\left(R_{k}-x(k)\right) \\
S(k+1)=C_{e} E=C_{e}\left(R_{k+1}-x(k+1)\right)=C_{e}\left[R_{k+1}-A x(k)-B u(k)\right]
\end{gathered}
$$

The novel reaching law's discrete form is:

$$
S(k+1)=(1-T q) S(k)-\varepsilon T \tan \operatorname{sig}\left(\|X\|_{1}\right) \operatorname{sgn}(S(k))
$$

From the above equation. The sliding mode control law of servo system is: $u(k)=\left(C_{e} B\right)^{-1}\left[C_{e} R_{k+1}-C_{e} A x(k)-(1-T q) S(k)+\varepsilon T \tan \operatorname{sig}\left(\|X\|_{1}\right) \operatorname{sgn}(S(k))\right]$

where: $C_{e}=[c, 1]$.

\section{Kalman Filtering Operator}

The continuous model of control system is converted into a discrete model; the discrete state equation and measurement equation are given as:

$$
x(k)=A x(k-1)+B(u(k)+w(k))
$$

$$
y_{v}(k)=C x(k)+v(k)
$$


Where $x(k)$ and $y_{v}(k)$ respectively are the state vector and observation vector. $A$ is the state matrix, $B$ is the control matrix, $C$ is the output observation matrix, $w(k)$ is the process noise signal, $v(k)$ is the observation noise signal.

The basic idea of kalman filter is to update the estimate of the state variables by using the state space model of signal and noise, and using the estimation of the last moment and the observation at the moment. The theory is suitable for real-time processing and computer arithmetic, and the kalman filter can effectively restrain the control interference signal and the measured noise signals which are may appear in the engineering through the estimation of the state of the system. The flow chart of kalman filtering algorithm is shown in Figure 3 [26].

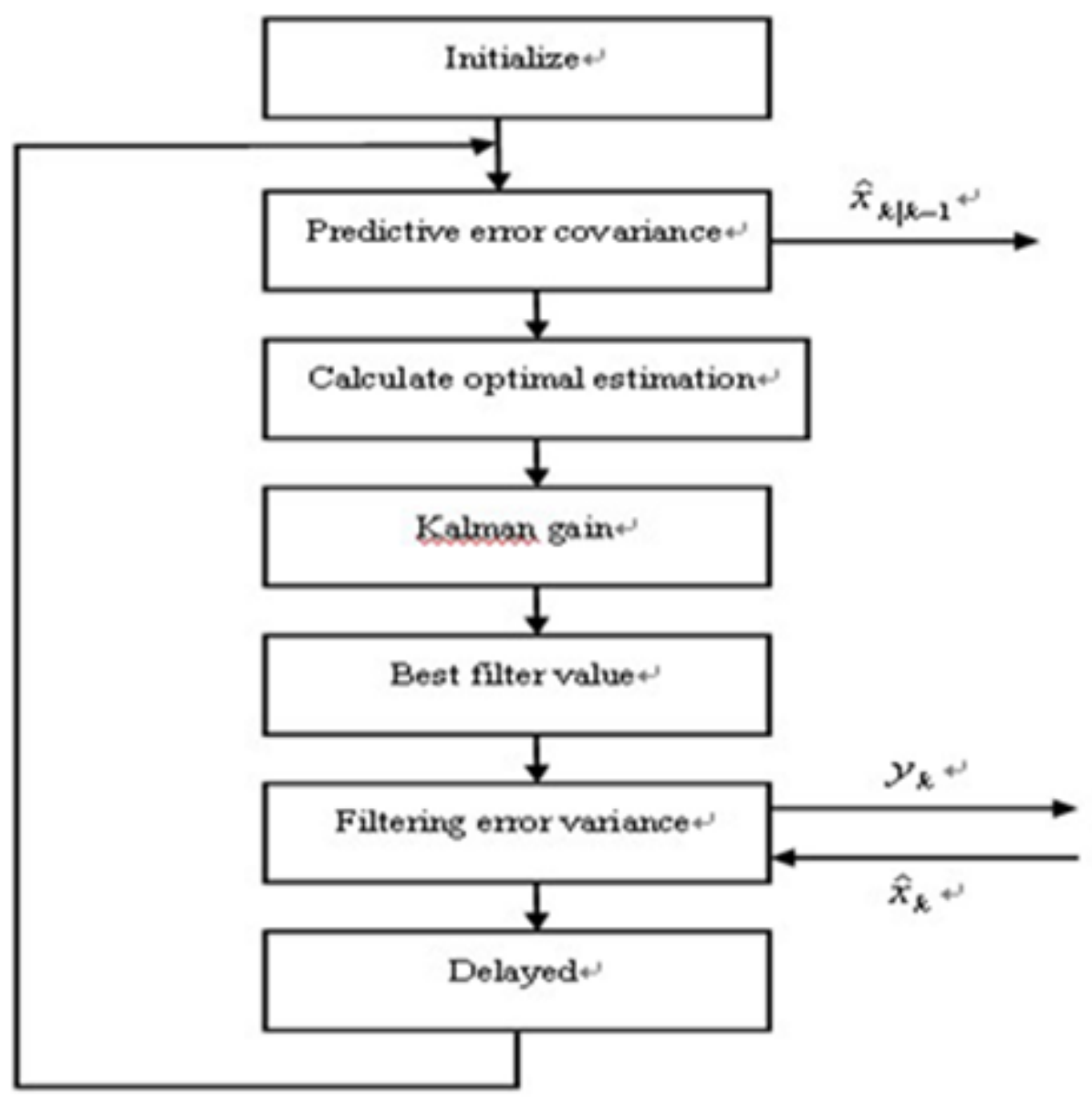

Figure 3. The Flow Chart of Kalman Filtering

The recursive algorithm of the corresponding kalman filter of flow chart is given as $[26,27]$ The best estimation is:

$$
\hat{x}_{k \mid k-1}=A_{k-1} \hat{x}_{k-1}
$$

The error variance of expect estimates is:

$$
P_{k \mid k-1}=A_{k-1} P_{k-1} A_{k-1}^{T}+B_{k-1} Q B_{k-1}^{T}
$$

The kalman gain is:

$$
K_{k}=p(k) C^{T}\left[C p(k) C^{T}+R\right]^{-1}
$$


The update estimation is:

$$
\hat{x}_{k}=A_{k-1} x_{k-1}+K_{k}\left(y_{v}-C A_{k-1} x_{k-1}\right)
$$

The updated estimate covariance is:

$$
P_{k}=\left(1-K_{k} C\right) P_{k \mid k-1}
$$

The output of filter is:

$$
y_{e}=C \hat{x}_{k}
$$

Where: $Q, R$ are the covariance matrix of random noise $w(k), v(k)$ respectively.

\section{Numerical Simulation}

In order to verify the effectiveness of the controller, use MATLAB to make simulation for the DC. The servo system's status equation [25]:

$$
\begin{gathered}
x(k)=A x(k-1)+B(u(k)+w(k)) \\
y_{v}(k)=C x(k)+v(k)
\end{gathered}
$$

Where:

$$
\begin{gathered}
A=\left[\begin{array}{cc}
1.0 & 0.0010 \\
0 & 1.9753
\end{array}\right], \quad B=\left[\begin{array}{ll}
0.000 & 0.1314
\end{array}\right] \\
C=\left[\begin{array}{ll}
1 & 0
\end{array}\right], \quad D=0 .
\end{gathered}
$$

$w(k)$ is the process white noise signal; $v(k)$ is the observation white noise signal. In order to prove the effect of system, the system with kalman filter and the system without kalman filter are respectively simulated. The simulation parameters are given as:

$$
c=40, \varepsilon=130, q=280, x=[-0.5,-0.5], \Delta=0.05 .
$$

The simulation results are given in the Figure 4-7:

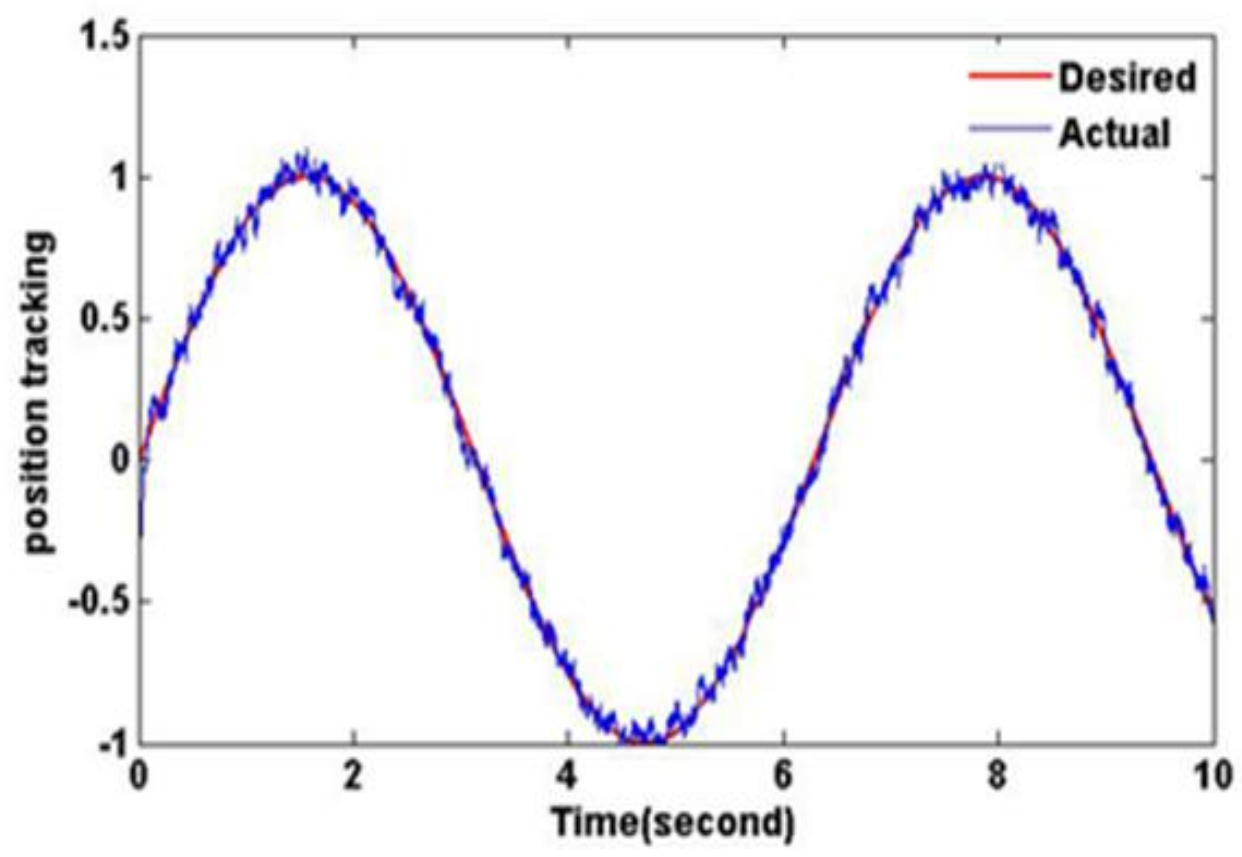

Figure 4. Position Trajectory without Filter Motor 


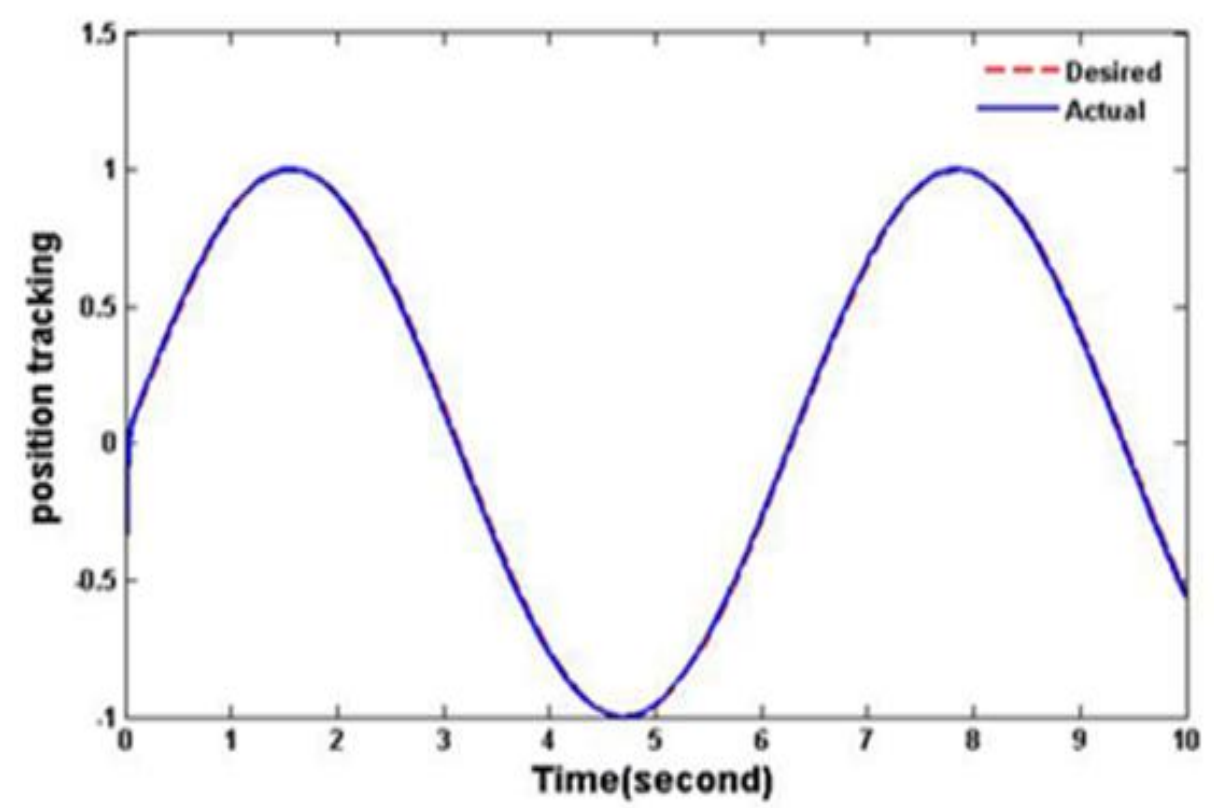

Figure 5. Position Trajectory with Filter Motor

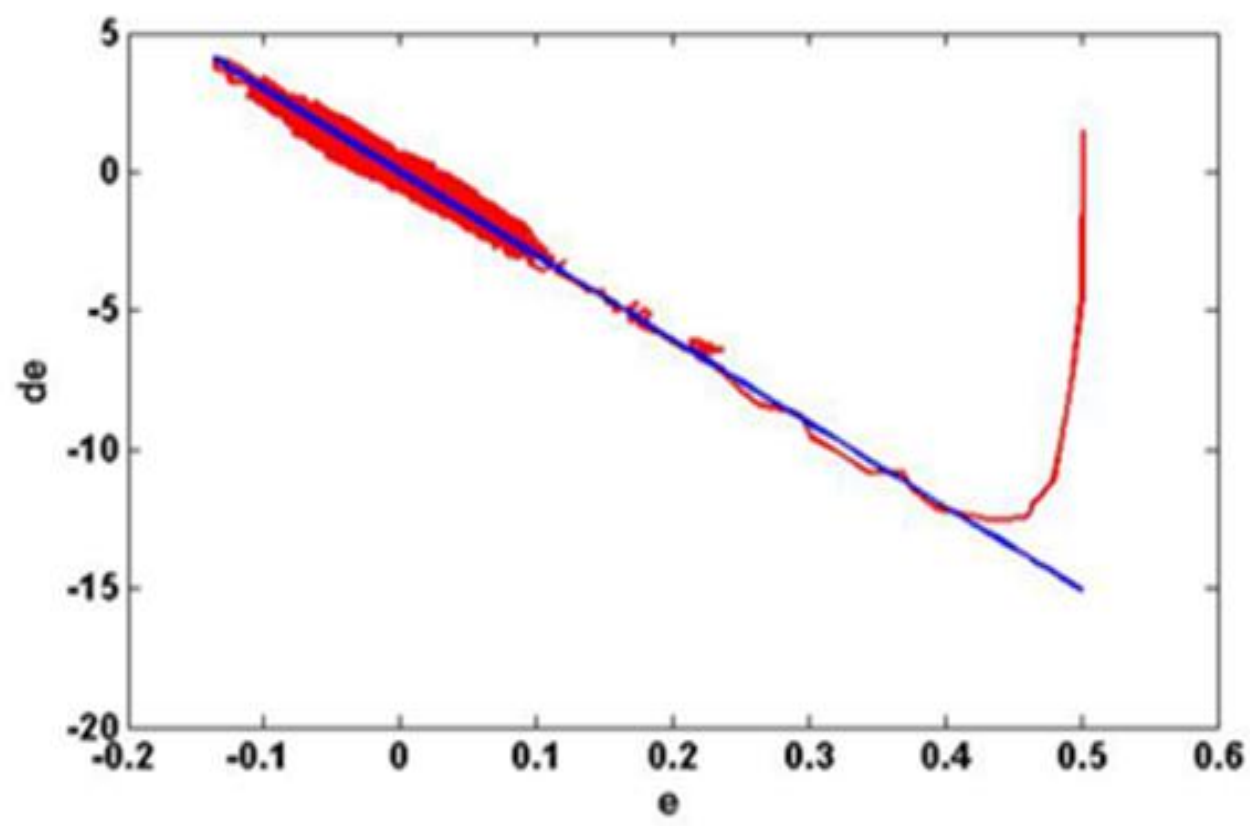

Figure 6. Phase Trajectory without Filter 


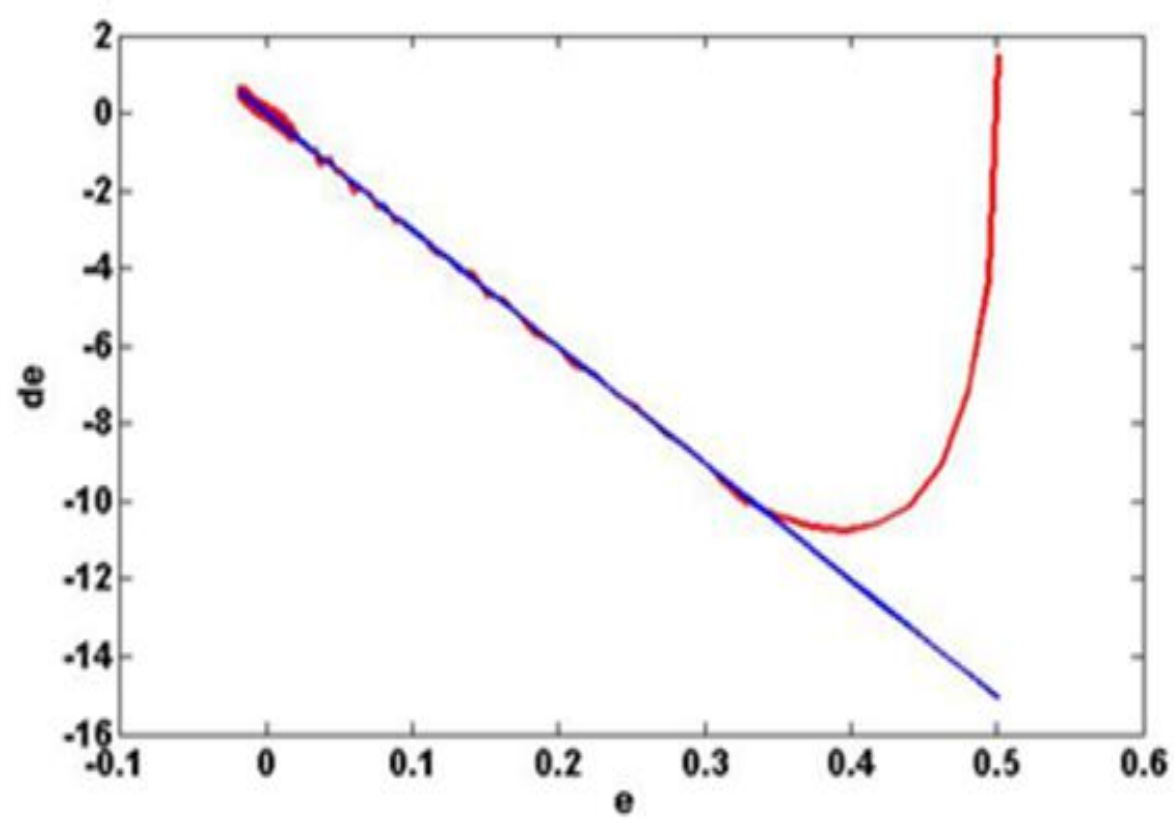

Figure 7. Phase Trajectory with Filter

The Figure 4-5 is the position trajectory. The Figure 6-7 is the Phase trajectory. From the simulation results (Figure 6-9) we can obtain the conclusions that the external disturbance and noise of system after adding kalman filter can be effectively restrained, the chattering of the sliding mode variable structure control is also inhibited, and can better realize the function of the controller.

\section{Conclusions}

This paper has proposed a sliding mode control algorithm with improved reaching law and kalman filter technology for the DC servo system, which can make the system have fast tracking performance and improve the ability of weakening the chattering. The simulation results show that the proposed control scheme can effectively improve the dynamic characteristic of the system, and has strong anti-interference ability and weaken the chattering ability. Aim at the inaccurately modeling and some uncertain existing in servo system seriously affected the control quality and the instability problem, the sliding mode variable structure is applied to the servo system. Considering the chattering problem of servo sliding mode variable structure control and the existing interference, which affect the quality and stability of system control, a reaching law approach is used to weaken the chattering problem existing in the sliding mode control. At the same time, kalman filter is used to inhibit the interference, thus to improve the quality and stability of servo system. System simulations show that the scheme can effectively suppress external disturbance and noise, which makes the system have strong anti-interference ability. And the chattering of the sliding mode variable structure control also had been obviously inhibited, the system stability and control quality has also been further improved. Stability and control quality been further improved.

\section{Current and Future Developments}

With the development of artificial intelligence, scholars have put forward many patents based on artificial intelligence to solve the chattering problems existing in the sliding mode control, such as the fuzzy method [28], neural network method [29-31], genetic optimization algorithm [32], etc. Variable Structure Control Theory as a comprehensive 
approach to a control system has been proposed for the second order linear system by Soviet scholars in the 1950s. After half a century of development, the theory has formed a relatively mature system; variable structure control is viewed as an important method of automatic control system design. It is suitable for linear and nonlinear systems, continuous time and discrete time systems, certain and uncertain system, lumped parameter and the distributed parameter systems and so on.

Many improved methods of reaching law, previously described, was largely based on Gao reaching law, however, these improvements of reducing the chattering were the cost of the strong robustness of the system. In the future, smoothing the control signal is an effective way to eliminate chattering through the use of filters. Simply reaching law or smoothing the control signal by the use of filters there are limitations by using which in solving the problem of chattering that existed in the variable structure control, so a kinds of control methods are combined to form a new control strategy based on the full analysis of a variety of advanced control strategies.

\section{Acknowledgements}

This work is supported by the Research Foundation of mathematics teaching team of Chaohu University (Ch12td01), the Research Foundation of Chaohu University(XLY201401).

\section{References}

[1] L. Jin-Kun and S. Fu-Chu, "Research and development on theory and algorithms of sliding mode control”, Control Theory and Applications, vol. 24, no. 3, (2007), pp. 407-412.

[2] Y. Yuji, "Sliding mode control method", E. P. Patent 0800125, (1997) October 8.

[3] W. B. Gao, "Theory foundation of Variable Structure Control", Beijing Science and Technology Press of China, Beijing, (1996).

[4] Nishida and Hideyuki, "Sliding mode control apparatus and adjusting method", W. O. Patent PCT/JP2006/319402, (2007) March 29.

[5] Glenn and C. Bradley, "Mass Flow Controller Employing Sliding mode control", W. O. Patent PCT/US2008/056005, (2009) September 11.

[6] Y. Dote and R. G. Hoft, "Microprocessor Based Sliding Mode Controller for DC motor drives", IAS Annual Meeting, (1980), Cincinnati, $\mathrm{OH}$.

[7] S. Z. Sarpturk, Y. Istefanopulos and O. Kaynak, "On the Stability of Discrete-time Sliding Mode [1] Control Systems", IEEE Trans, vol. 32, no. 10, (1987), pp. 930-932.

[8] K. Furuta, "Sliding Mode Control of a Discrete System", Systems \& Control Letters, vol. 14, (1990), pp. 145-152.

[9] H. Yao, L. Son and H. Wen, "The proportion of discrete variable structure system - uniform - variable speed control", Control and Decision, vol.15, no. 3, (2000), pp. 329-332.

[10] C. Zhai and Z. Wu, "An improved discrete time variable structure control system", Computing technology and automation, vol. 18, no. 2, (1999), pp. 27-31.

[11] J. Zhou, Y. Xiao and H. Jiang, "The attenuation of discrete variable structure system variable speed control", Basic automation, vol. 8, no. 5, (2001), pp. 16-18.

[12] W. Li, "ODiscrete time variable structure control system of the reaching law", Control and Decision, vol. 19, no. 11, (2004), pp. 1267-1270.

[13] Z. Li, X. Zhang and X. Li, "An improved discrete time variable structure control system", Electric machines and control, vol. 9, no. 1, (2005), pp. 90-92.

[14] C. Gao, Y. Liu and Y. Li, "Uncertain discrete-time variable structure control system of the reaching law method", Control Theory \& Applications, vol. 26, no. 7, (2009), pp. 781-785.

[15] W. C. Su, S. V. Drakunov and U. Ozguner, "Sliding mode with chattering reduction in sampled data systems", Proc. of the 32nd IEEE Conf. on Decision and Control, (1993), pp. 2452 - 2457.

[16] P. Kachroo and M. Tomizuka, "Chattering reduction and error convergence in the sliding-mode control of a class of nonlinear systems", IEEE Trans on Automatic Control, vol. 41, no. 7, (1996), pp. 10631068.

[17] B. P. Kang and J. L. Ju, "Sliding mode controller with filtered signal for robot manipulators using virtual plant/controller", Mechatronics, vol. 7, no. 3, (1997), pp. 277 - 286.

[18] Y. D. H. Ohnishi, "Frequency-shaped sliding mode control of an electrohydraulic servo-motor", J of Systems and Control and Dynamics, vol. 213, no. 1, (1999), pp. 441-448.

[19] D. Krupp and Y. B. Shtessel, "Chattering-free sliding mode control with un-modeled dynamics", Proc. of American Control Conf. San Diego, IEEE Press, (1999), pp. 530 - 534. 
[20] J. X. Xu, Y. J. Pan and T. H. LEE, "A gain scheduled sliding mode control scheme using filtering techniques with applications to multi-link robotic manipulators", J of Dynamic Systems, Measurement and Control, vol. 122, no. 4, (2000), pp. $641-649$.

[21] H. L, F. Q. W and H. C. X, "Design for Mechanical Integration System", Higher education press, Beijing, (2011).

[22] M. S. S. Ahmed, Z. Ping and W. Y. Jie, "Modified sliding mode controller with extended Kalman Filter for stochastic systems", IEEE international conference on control and automation, (2007), pp. 630-635.

[23] K. B. Park and J. J. Lee, "Sliding mode controller with filtered signal for robot manipulators using virtual plant controller," J of Mechatronics, vol. 7, (1997), pp. 277-286.

[24] K. W. Tong, X. Zhang, Y. Zhang, Z. Xie and R. X. Cao, "Sliding Mode Variable Structure Control of Permanent Magnet Synchronous Machine Based on a Novel Reaching Law", J of Proceedings of the CSEE, vol. 28, (2008), pp. 102-106.

[25] G. Cun-Chen, L. Yun-Long and L. Yun-Yan, "A reaching-law method for uncertain discrete variablestructure control systems", Control Theory \& Applications, vol. 26, no. 7, (2009), pp. 781-785.

[26] J. K. Liu, "MATLAB Simulation for Sliding Mode Control", Tsinghua University Press, Beijing, (2005)

[27] Z. You-Wei, “An Introduction for Winer and kalman filter heory", People's Education Press, Beijing, (1980).

[28] J. A Stanley, "Elevator car dispatching including passenger destination information and a fuzzy logic algorithm", U. S. Patent 11214089, (2007) January 3.

[29] Hobson and P. William, "Monitoring and Retraining Neural Network, C. A. Patent 2249316, (1998) July 23.

[30] A. Nogaret, "Neural Network", W. O. Patent PCT/GB2013/051178, (2013) November 8.

[31] Cho Il, "Apparatus and method for estimating state of charge in battery using fuzzy algorithm implemented as neural network", U. S. Patent 12869242, (2010) December 23.

[32] M. Akiharu, "Microprocessor using genetic algorithm", U. S. Patent 10878011, (2005) June 1.

\section{Authors}

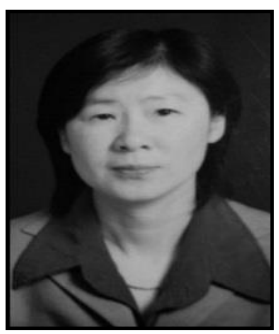

Min Ma, She received the Bachelor's degree in department of mathematics from YangZhou Normal University, in 1983. Now she is an associate professor at basic education department of Jiangsu Food \& Pharmaceutical Science College. Her current research interests include different aspects of Applied Mathematics and Data Analysis.

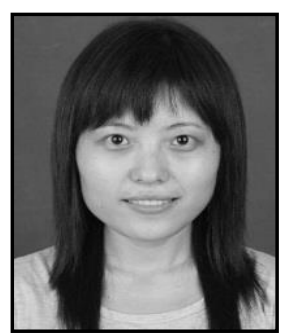

Jueping Bu, She received the Master degree in department of mathematics from central south university, in2009. Currently, she is a teaching assistant at department of mathematics, ChaoHu University. Her research interests include different aspects of Ordinary Differential Equation and Control Engineering.

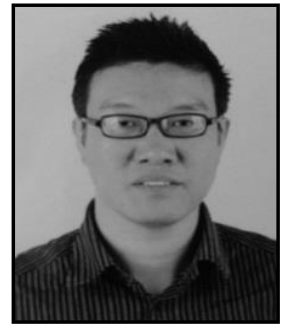

Miaochao Chen, He received the Master degree in department of mathematics from Southeast University, in 2011. Currently, he is a lecturer at department of mathematics, ChaoHu University. His research interests include different aspects of Partial Differential Equation and Control Engineering. 
International Journal of Signal Processing, Image Processing and Pattern Recognition Vol. 8, No. 4 (2015) 